\title{
VALUASI EKONOMI DAN DAMPAK LINGKUNGAN AKIBAT INDUSTRI PENGOLAHAN MARMER DI DESA BESOLE KABUPATEN TULUNGAGUNG DI TINJAU DARI ESDAL PESPEKTIF ISLAM ${ }^{1)}$
}

\author{
Silfi Indririyani \\ Program Studi S1 Ekonomi Islam-Fakultas Ekonomi dan Bisnis-Universitas Airlangga \\ Email : silfi.indririyani@gmail.com \\ Moh Qudsi Fauzy \\ Departemen Ekonomi Syariah-Fakultas Ekonomi dan Bisnis-Universitas Airlangga \\ Email: qudsufauzyl@gmail.com
}

\begin{abstract}
:
The existence of the marble processing industry in Tulungagung Besole village has an impact both economic and environmental impact.This study calculating the economic valuation of the marble industry tod eterminethefeasibility of the industry when seenin the economic and environmental impact generated by natural resource economics review Islamic perspective. Use of ESDAL Islamic perspective is intended to determine how the rules of Islam in governing the use and maintenance of nature, and to know if the marble business in the village Besole have run the rule.Results of the study found that the marble processing industry economically feasible. However, theprocessing of marble that have a negative impact on the environment and society, like a air pollution, pollution caused by solid waste, and also a form of energy that is noise pollution
\end{abstract}

Keywords: Marble Industry, Economic Valuation, Environmental Impact, esdal perspektif Islam

\section{PENDAHULUAN}

Latar Belakang

Manusia menempati posisi terpenting dalam melindungi lingkungan hidup dari kerusakan dan kemerosotan mutu serta untuk menjamin kelestariannya.

Qadir (1997:124) menjelaskan Islam memandang penataan lingkungan menjadi tanggung jawab manusia sebagai khalifah di bumi. Tanggung jawab manusia terletak pada penataan, pemeliharaan, pengawasan dan pengembangan tata lingkungan yang bermanfaat bagi manusia. Salah satu pemanfaatan sumber daya alam yang bisa di lakukan oleh manusia adalah melalui pengelolaan sumber daya alam melalui industri. Dalam UU Perindustrian No.5 Tahun 1984, industri adalah kegiatan ekonomi yang mengelola bahan mentah, bahan baku, barang setengah jadi, dan atau barang jadi menjadi barang dengan nilai yang lebih tinggi untuk penggunaannya termasuk kegiatan rancangan bangun dan perekayasaan industri

$\begin{array}{ccc}\text { Kabupaten } & \text { Tulungagung } \\ \text { merupakan salah satu daerah di }\end{array}$
Indonesia yang memiliki kekayaan sumber daya alam berupa batu marmer. Daerah ini memiliki kondisi topografi yang didominasi oleh struktur batuan yang beraneka ragam. Hal ini membuat daerah tersebut kaya akan potensi bahan galian golongan $\mathrm{C}$ terutama bahan galian batu marmer. Khususnya di Desa Besole sumber daya bahan galian marmer sangat besar yaitu sebanyak 9.855 .000 ton. Potensi galian yang ada di Desa Besole ini berkembang menjadi industri marmer 1) Jurnal ini merupakan bagian dari skripsi Silfi Indririyani, NIM : 041211431170 , yang diuji pada 4 April 2016 
Indririyani, et al/Jurnal Ekonomi Syariah Teori dan Terapan Vol. 3 No. 8 Agustus 2016: 643-655; VALUASI EKONOMI DAN DAMPAK LINGKUNGAN AKIBAT INDUSTRI PENGOLAHAN MARMER DI DESA BESOLE KABUPATEN TULUNGAGUNG DI TINJAU DARI ESDAL PESPEKTIF ISLAM

yang bermula sejak tahun 1961 dan berpusat di Desa Besole. Kemudahan dalam memperoleh bahan baku menjadikan industri marmer di Kabupaten Tulungagung berkembang dengan pesat dan cepat merambah pasar nasional dan internasional. Jumlah industri marmer yang ada di desa besole sendiri berjumlah kurang lebih 80 unit dengan jumlah tenaga kerja sejumlah 4800 orang. Pesatnya perkembangan dan pertumbuhan industri pengolahan marmer yang ada di Desa Besole ini memberikan dampak secara ekonomi dengan peningkatan pendapatan dan terbukanya lapangan pekerjaan. Namun, damak lain yang ikut muncul dari aktivitas industri pengolahan marmer tersebut adalah dampak terhadap lingkungan. Perkembangan industri pengolahan marmer tersebut tidak diiringi dengan pengelolaan limbah yang baik oleh para pelaku industri. Masih banyaknya tempat pengolahan marmer yang belum memiliki tempat pembuangan limbah berupa lumpur yang memadai merupakan salah satu penyebab terjadinya pencemaran. Selain itu dampak adanya industri pengolahan marmer tersebut juga dirasakan oleh masayarakat yang tinggal berdekatan dengan industri yaitu berupa pencemaran udara akibat banyaknya debu yang disebabkan oleh lalu lalang truk yang mengangkut bahan baku marmer, serta pencemaran energi berupa kebisingan yang ditimbulkan dari suara mesin pemotong marmer.
Penelitian ini akan berupaya mengetahui kelayakan industri pengolahan marmer secara ekonomi dengan pendekatan valuasi ekonomi. Metode yang digunakan untuk menentukan valuasi tersebut adalah dengan metode ne present value (NPV) dan benefit cost rasio (BCR). Selain melakukan perhitungan valuasi untuk mengetahui kelayakan secara ekonomi juga akan dilakukan pendekatan ekonomi sumber daya alam dan lingkungan perspektif islam (ESDAL perspekti Islam) untuk mengetahui bagaimana kaidah islam dalam mengatur pemanfaatan dan pemeliharaan alam, dan untuk mengetahui apakah para pelaku usaha marmer di Desa Besole telah menjalankan kaidah tersebut.

\section{TINJAUAN PUSTAKA}

Menurut Reksohadiprojo (1988:17) bahasan mengenai ekonomi lingkungan berangkat dari logika sederhana bahwa ekonomi adalah bagian tak terpisahkan dari lingkungan. Ekonomi lingkungan mempelajari usaha manusia mengalokasikan sumberdaya sedemikian rupa sehingga kebutuhannya terpenuhi dan sekaligus membatasi pencemaran lingkungan.Kusumastanto dalam Putrantomo (2010: 18) menjelaskan valuasi ekonomi adalah nilai ekonomi yang terkandung dalam suatu sumberdaya alam, baik nilai guna maupun nilai fungsional yang harus diperhitungkan dalam menyusun kebijakan pengelolaannya sehingga alokasi dan 
Indririyani, et al/Jurnal Ekonomi Syariah Teori dan Terapan Vol. 3 No. 8 Agustus 2016: 643-655; VALUASI EKONOMI DAN DAMPAK LINGKUNGAN AKIBAT INDUSTRI PENGOLAHAN MARMER DI DESA BESOLE KABUPATEN TULUNGAGUNG DI TINJAU DARI ESDAL PESPEKTIF ISLAM

alternatif penggunaannya dapat ditentukan secara benar dan mengenai sasaran. Pendekatan valuasi ekonomi dalam penelitian ini menggunakan metode perhitungan NPV dan BCR.

$\mathrm{NPV}=\sum \frac{B t}{(1+r)^{t}} \sum \frac{C t}{(1+r)}$

Keterangan :

NPV = Net present value

B = Manfaat (Benefit)

C = Biaya (cost)

$r \quad=$ Tingkat diskonto

$\dagger \quad=$ waktu

$\Sigma \quad=$ Jumlah

Apabila NPV $>0$ maka proyek atau kegiatan yang dilakukan dianggap layak dan sebaliknya apabila NPV $<0$, proyek atau kegiaan tersebut dinyatakan tidak layak (Suparmoko, 2009:72)

$\mathrm{BCR}=\frac{\sum_{t-n}^{T} \frac{M_{t}}{(1+i)^{t}}}{\sum_{t-n}^{T} \frac{B t}{(1+i)^{t}}}$

Berdasarkan Metode ini, suatu Proyek akan dilaksanakan apabila BCR > 1, dan sebaliknya suatu proyek tidak dilakasanakan apabila BCR $<1$. Ada beberapa kelebihan dan kelemahan msing-masing metode analisis seperti ditunjukkan dalam tabel berikut.

Undang-undang nomor 32 tahun 2009 tentang perlindungan dan pengelolaan lingkungan hidup, dampak lingkungan didefinisikan sebagai suatu perubahan lingkungan hidup yang diakibatkan oleh suatu dan atau kegiatan. Sementara itu, Soemarwoto
(1994:43) mendefinisikan dampak sebagai suatu perubahan yang terjadi sebagai akibat suatu aktivitas di mana aktivitas tersebut dapat bersifat alamiah, baik kimia, fisik, dan biologi. Lebih lanjut didefinisikan dampak pembangunan terhadap lingkungan adalah perbedaan antara kondisi lingkungan sebelum ada pembangunan dan yang diperkirakan akan ada setelah ada pembangunan

Pencemaran dapat diklasifikasikan dalam bermacam-macam bentuk menurut pola pengelompokannya berkaitan dengan itu, Amsyari (1996:102), mengelompokkan pencemaran atas dasar :

a. Bahan pencemar yang menghasilkan pencemaran biologis, kimiawi, fisik, dan budaya

b. Pengelompokan berdasarkan medium lingkungan menghasilkan bentuk pencemaran udara, air, tanah, makanan dan sosial

c. Pengelompokan menurut sifat sumber menghasilkan pencemaran dalam bentuk primer dan sekunder

Berdasarkan peraturan pemerintah No.18/1999 Jo.PP 85/1999. Limbah didefinisikan sebagai sisa atau buangan dari suatu usaha dan atau kegiatan manusia. Limbah adalah bahan buangan tidak terpakai yang berdampak negatif terhadap masyarakat jika tidak dikelola dengan baik. Limbah marmer adalah limbah yang dihasilkan pada saat proses pengolahan batu marmer menjadi 
Indririyani, et al/Jurnal Ekonomi Syariah Teori dan Terapan Vol. 3 No. 8 Agustus 2016: 643-655; VALUASI EKONOMI DAN DAMPAK LINGKUNGAN AKIBAT INDUSTRI PENGOLAHAN MARMER DI DESA BESOLE KABUPATEN TULUNGAGUNG DI TINJAU DARI ESDAL PESPEKTIF ISLAM

macam-macam bentuk kerajinan. Ada yang diproses menjadi meja, patung, tegel, dan juga berbagai macam kerajinan yang lain. Dalam proses pembuatan kerajinan itulah batu marmer yang semula berukuran besar dipotong menjadi berbagai ukuran menurut kebutuhan dengan menggunakan gergaji. Selama melakukan penggergajian inilah di peroleh limbah marmer yang berlimpah.

Dari sifat-sifat dan atau wujud fisiknya limbah atau komponen polutan dapat dibagi menjadi sebagai berikut (Soeharto, 2001: 212-217):

1. Limbah cair

Limbah cair adalah buangan limbah yang mengandung kadar air cukup tinggi. Limbah jenis ini umumnya berasal dari industri yang dalam operasinya banyak berkaitan dengan air, baik yang semula diperlukan untuk proses produksi maupun terbawa oleh bahan baku yang perlu dikeluarkan atau dari air cucian tempat dimana proses produksi berlangsung

2. Limbah pencemaran udara Limbah padat buangan industri atau sampah domestik dapat berupa bubur, lumpur atau betul-betul padat. Limbah padat yang terdiri dari berbagai material dan senyawa tertumpuk, misalnya di pembuangan/pengumpulan sampah terbuka, lambat laun akan mengalami reaksi pembusukan dan mengeluarkan zat pencemaran terhadap udara dan dapat larut dalam air yang mengalir di waktu hujan

3. Limbah padat

Pencemaran energi terdiri dari kebisingan dan panas. Kebisingan diartikan sebagai suara yang tidak diinginkan. Kebisingan dengan intensitas dan lama waktu tertentu dapat mengurangi kenyamanan (mengganggu ketenangan dan mengacau konsentrasi) bahkan juga merusak daya pendengaran seseorang. Suhu air pendingin buangan dari instalasi industri seringkali lebih tinggi dari suhu air di tempat penerima (sungai, danau atau pantai). Kenaikan suhu lingkungan akibat pembuangan air ini dapat mengganggu kehidupan berbagai jenis biota yang ada di tempat penerima.

Menurut Wihardi (2006:40),

kandungan kimia pecahan marmer mengandung $55,07 \%$ Kalsium Oksidasi (CaO) dan unsur - unsur kimia lainnya. Hasil analisa kimia pecahan marmerdapat dilihat pada tabel

Tabel 1

Unsur Kimia Limbah Marmer

\begin{tabular}{|l|c|}
\hline \multicolumn{1}{|c|}{ Oksidasi } & $\begin{array}{c}\text { Kandungan } \\
\mathbf{( \% )}\end{array}$ \\
\hline Kalsium Oksida (CaO) & $\mathbf{5 , 6 9}$ \\
\hline Silikon Diosida (SiO2) & $\mathbf{0 , 1 3}$ \\
\hline AluminiumDioksida (AlO3) & $\mathbf{0 , 3 1}$ \\
\hline FeriOksida (FeO3) & $\mathbf{0 , 0 4}$ \\
\hline $\begin{array}{l}\text { Magnesium Oksida } \\
\text { (MgO) }\end{array}$ & $\mathbf{0 , 3 6}$ \\
\hline Potash (K2O) & $\mathbf{0 . 0 1}$ \\
\hline Sulfur Trioksida (SO3) & $\mathbf{0 , 0 8}$ \\
\hline Lol & $\mathbf{4 4 , 0}$ \\
\hline
\end{tabular}

Sumber: wihardi dkk 2006:3

Menurut Najwan

(2010)

Pemeliharaan lingkungan hidup

merupakan penentu keseimbangan alam.

Dalam konteks pelestarian. lingkungan, pemahaman ini sudah kita dengar sejak lama. Bahkan, pelajaran ilmu alam seolah tidak henti hentinya mengajarkan bahwa semua komponen ekosistem baik berwujud makhluk hidup 
Indririyani, et al/Jurnal Ekonomi Syariah Teori dan Terapan Vol. 3 No. 8 Agustus 2016: 643-655; VALUASI EKONOMI DAN DAMPAK LINGKUNGAN AKIBAT INDUSTRI PENGOLAHAN MARMER DI DESA BESOLE KABUPATEN TULUNGAGUNG DI TINJAU DARI ESDAL PESPEKTIF ISLAM

maupun.komponen alam lainnya, merupakan sebuah kesatuan yang harus berjalan seimbang dan tidak boleh timpang satu dengan yang lain.

Najwan (2010: 63) menjelakan bahwa setelah manusia memahami hakikat dirinya dan hakikat alam yang ditinggalinya, maka manusia akan mengetahui apa yang harus diperbuat terhadap sumber daya alam yang disediakan baginya itu. Sehinga manusia sebenarnya tidak perlu mempunyai masalah tentang pengelolaan sumber daya itu, jika dia mematuhi aturan main yang telah disepakatinya. Sehubungan dengan pengelolaan sumber daya tersebut, Islam mengatur hal-hal sebagai berikut:

1. Tidak membuat kerusakan dibumi

2. Bersahabat dengan alam

3. Tidak berlaku boros

4. Memikirkan generasi yang akan datang

5. Meningkatkan kesejahteraan umum Menurut safrilsyah dan fitriani (2014:67) menjelaskan bahwa seorang ulama islam kontemporer yusuf al qarhawi, telah banyak mengulas tentang hubungan islam dan lingkungan hidup dalam beberapa fatwa dan tulisannya. Terdapat beberapa term dalam agama islam yang dapat dikaitkan dengan pemelihaaan lingkungan hidup diantaranya adalah AlIstishlah dan Pendekatan tujuan dasar islam (maqasid syariah).

\section{METODE PENELETIAN}

Tahapan awa dalam penelitian ini dilakuakn dengan kegiatan wawancara, observasi dan studi pustaka. Wawancara dilakukan dengan lima pemilik tempat pengolhan marmer dan juga masayarakat yang memiliki tempat tinggal berdekatan dengan tempat pengolahan marmer yang berlokasi di Desa Besole Kabupaten Tulungagung. Penelitian ini menggunakan teknik Purposive sampling dalam mendapatkan informan. Menurut Sugiyono (2008: 18) purposive sampling adalah teknik pengambilan sampel sumber data dengan pertimbangan tertentu. Dalam penelitian ini informa yang di ambil terdiri dari para pelaku usaha industri marmer dan masyarakat yang berada di sekitar area industri yang ada di Desa Besole dengan beberapa kriteria sebagai berikut

1. Pelaku usaha industri marmer

a. Industri telah berjalan lebih dari 5 tahun

b. Memiliki jumlah karyawan sedikitnya 5 orang

c. Memiliki mesin pengolah marmer sedikitnya 1 buah

d. Lokasi industri berdekatan dengan pemukiman kurang lebih radius 100 meter

2. Masyarakat

a. Telah berdomisili dalam rentan waktu minimal 10 sampai 30 tahun 
Indririyani, et al/Jurnal Ekonomi Syariah Teori dan Terapan Vol. 3 No. 8 Agustus 2016: 643-655; VALUASI EKONOMI DAN DAMPAK LINGKUNGAN AKIBAT INDUSTRI PENGOLAHAN MARMER DI DESA BESOLE KABUPATEN TULUNGAGUNG DI TINJAU DARI ESDAL PESPEKTIF ISLAM
b. Kriteria umur mulai dari anak- anak hingga dewasa
c. Lokasi rumah berdekatan dengan industri marmer kurang lebih radius 100 meter

Selanjutnya, mengidentifikasi kebutuhan data baik data primer maupun data sekunder yang adakn dipergunakan dalam tahapan penelitianselanjutnya. Data primer diperoleh memalui proses wawancara, observasi serta dikumentasi, sedangkan data sekunder didapat dari penelitian sebelumnya, jurnal, buku dan lain-lain.

Teknik pengumpulan data menggunakan multi sumber bukti (triangulasi) artinya teknik pengumpulan data yang bersifat menggabungkan dari berbagai teknik pengumpulan data dan sumber data yang telah ada. Triangulasi teknik berarti peneliti menggunakan teknik pengumpulan data yang berbeda-beda untuk mendapatkan data dari sumber yang sama. Peneliti akan menggunakan observasi partisipatif, wawancara mendalam, dan dokumentasi untuk sumber data yang sama secara serempak (Sugiono, 2008:83)

\section{HASIL DAN PEMBAHASAN}

Secara geografis Kabupaten Tulungagung terletak antara koordinat $111^{\circ} 43^{\prime} 00^{\prime \prime}$ - 112 $07^{\prime} 00^{\prime \prime}$ BT dan 7051'00" $8^{\circ} 18^{\prime} 00^{\prime \prime}$ LS. Kabupaten Tulungagung merupakan salah satu dari 38 kabupaten/kota di Provinsi Jawa Timur.
Wilayah bagian Selatan Kabupate Tulungagung merupakan pegunungan kars yang menurut penelitian Dinas Energi Sumber Daya Mineral pada Tahun 2002 mempunyai kandungan marmer sebesar $382.050 .000 \mathrm{~m}^{3}$ yang tersebar di Kecamatan Besuki, Campurdarat, Tanggunggunung Kalidawir dan Kecamatan Rejotanga. Perkembangan pertambangan di Kabupaten Tulungagung yang paling banyak di eksploitasai dalah marmer yang terdapat di Kecamatan Besuki tepatnya di desa Besole dengan volume produksi mencapai 15,731.738 rnt dan merupakan produk unggulan Kabupaten Tulungagung.

Desa Besole sendiri memiliki jumlah penduduk sebesar 11.225 jiwa dengan luas wilayah $6,96 \mathrm{~km}^{2}$. Jumlah industri marmer yang ada di desa besole sendiri berjumlah kurang lebih 80 unit dengan jumlah tenaga kerja sejumlah 4800 orang. Perkembangan marmer di Tulungagung diawali dengan ditemukannya lokasi pertambangan marmer oleh penjajah Hindia-Belanda sekitar tahun 1934. Lokasinya bertempat di sekitar desa Besole kecamatan Besuki Kabupaten Tulungagung.

Mayoritas pengolahan marmer yang dilakukan oleh masyarakat masih menggunakan teknik tradisional yaitu dengan memotong gelondongan batu marmer menggunakan mesin potong yang digerakkan angan tenaga diesel. Gelondongan marmer tersebut dipotong 
Indririyani, et al/Jurnal Ekonomi Syariah Teori dan Terapan Vol. 3 No. 8 Agustus 2016: 643-655; VALUASI EKONOMI DAN DAMPAK LINGKUNGAN AKIBAT INDUSTRI PENGOLAHAN MARMER DI DESA BESOLE KABUPATEN TULUNGAGUNG DI TINJAU DARI ESDAL PESPEKTIF ISLAM

menjadi bagian bagian kecil yang kemudian di lakukan pemotongan lagi sesuai ukuran dan jenis produk yang diproduksi. Adanya industri pengolahan marmer memberikan dampak secara ekomi dengan peningkatan pendapatan dan terbukanya lapangan pekerjaan. Namun, damak lain yang ikut muncul dari aktivitas industri pengolahan marmer tersebut adalah dampak terhadap lingkungan. Dampak lingkungan ini muncul dikarenakan para pemilik tempat pengolahan marmer sering kali mengabaikan limbah yang dihasilkan dari proses produksi seperti limbah berupa lumpur, bedu yang dihasilkan dari lalu lalang truck pengangkut bahan baku, dan juga kebisingan dari suara mesin pemotong marmer. Dengan adanya dampak positif dari sisi ekonomi dan juga dampak negatif dari sisi lingkungan maka peneliti akan melakukan analisis perhitungan valuasi ekonomi dengan metode NPV danBCR untuk mengetahui kelayakan tempat pengolahan marmer secara ekonomi dan melakukan tinjaual ESDAL perspektif islam yang dimaksudkan untuk mengetahui bagaimana kaidah islam dalam mengatur pemanfaatan dan pemeliharaan alam, dan untuk mengetahui apakah para pelaku usaha marmer di Desa Besole telah menjalankan kaidah tersebut.

A. Analisis valuasi ekonomi tempat pengolahan limbah marmer dengan perhitungan NPV dan BCR.
Pada dasarnya perhitungan valuasi ekonomi memiliki beberapa metode pendekatan. Pendekatan yang umum dilakukan adalah dengan perhitungan analisis manfaat dan biaya dengan metodeNPV (Net present value) dan BCR (benefit cost ratio). Pendapatan dari industri marmer ini tergantung dari ada tidaknya pesanan serta kemampuan industri tersebut dalam memproduksi (memotong) lembar marmer, sehingga penghasilan perbulannya sangat bervariatif.

Di sini dilakukan wawancara kepada lima pelaku industri marmer yang ada di Desa Besole Kabupaten Tulungagung. Lima informan memberikan rata-rata pendapatan yang didapat dari tempat pengolahan marmer dan biaya yang dikeluarkan oleh masing-masing informan untuk kegiatan produksi, namun data yang dapat diberikan hanya terbatas pada tahun 2015 saja. Hal ini dikarenakan mereka tidak melakukan pencatatan terhadap pendapatan dan biaya setiap tahunnya.

Berikut hasil perhitungan NPV dan BCR dari kelima industri pengolah marmer yang ada di Desa Besole

Tabel 2

Rangkuman NPV dan BCR

\begin{tabular}{|l|l|l|}
\hline Informan & $\mathrm{NPV}$ & $\mathrm{BCR}$ \\
\hline Informan 1 & 24.813 .616 & 1,23 \\
\hline Informan 2 & 44.827 .232 & 1,36 \\
\hline Informan 3 & 46.378 .348 & 1,38 \\
\hline Informan 4 & 219.228 .795 & 1,71 \\
\hline
\end{tabular}


Indririyani, et al/Jurnal Ekonomi Syariah Teori dan Terapan Vol. 3 No. 8 Agustus 2016: 643-655; VALUASI EKONOMI DAN DAMPAK LINGKUNGAN AKIBAT INDUSTRI PENGOLAHAN MARMER DI DESA BESOLE KABUPATEN TULUNGAGUNG DI TINJAU DARI ESDAL PESPEKTIF ISLAM

\begin{tabular}{|l|l|l|}
\hline Informan 5 & 59.982 .366 & 1,38 \\
\hline
\end{tabular}

Sumber: Diolah Penulis, 2015

Kelima industri pengolahan marmer di atas menunjukkan nilai NPV> 0 dan BCR>1Hal ini menunjukkan bahwa kelima tempat pengolahan marmer tersebut layak untuk dilakukan secara ekonomi, namun dari sisi lingkungan pengolahan marmer tersebut masih belum bisa dikatakan layak. Hal ini dikarenakan masih belum memadainya tempat pembuangan limbah dadi sisa pemotongan marmer yang berupa Iumpur. Kebanyakan tempat pengolahan marmer ini membuang limbah lumpur ini ke dalam kolam tanah yang mereka buat di sekitar tempat pengolahan.

B. Kesesuaian Tempat Pengolahan Marmer Dalam melakukan pemanfaatan SDA

Indikator kesesuaian pemanfaatan SDA dalam islam terditi dari tidak membuat kerusakan di bumi, bersahabat dengan alam, tidak berlaku boros, memikirkan generasi yang akan datang dan meningkatkan kesejahteraan umum. Kelima informan yang terdiri dari para pemilik industri tersebut dalam memberikan pendapatnya terkair kesesuaian tempat pengolahan marmer dalam melakukan pemanfaatan SDA memberikan pendapat yang beragam. Semua informan memberikan pendapat yang hampir seragam. Dari kelima indikator kesesuain pemanfatan dan pengolahan SDA dapat diketahui bahwa informan belum sepenuhnya memenuhinya. Hal ini terlihat dari wawancara yang peneliti lakukan bahwa para pelaku industri ini cenderung membiarkan segala sesuatunya seperti enggannya mereka untuk membuat tempat penampungan limbah yang memadai. Alasan yang mereka tuturkan adalah karena tidak tersedianya biaya serta karena para pelaku industri marmer disana kebanyakan pada umumnya menampung limbah dari pengolahan marmer tersebut didalam kolam tanah. Dari kelima indikator tersebut indikator kelima yaitu meningktkan kesejahteraan umum yang paling mendekati sesuai. Hal ini ditunjukkan dar hasil wawancara yang menunjukkan bahwa kelima informan senantiasa ikut berkontribusi dalam kegiatan yang dialakukan oleh lingkunagan sekitar dan juga para informan menyisihkan pendapatannya untuk bershodagoh dan membantu tetangga yang membutuhkan.

Tabel 3

Kesesuaian Pemanfaatan SDA

\begin{tabular}{|c|c|c|}
\hline No & Informan & Kesesuaian Pemanfaatan SDA \\
\hline 1 & Informan 1 & $\begin{array}{l}\text { Tempat pembuangan limbah tidak } \\
\text { sesuai, kurang pemahaman akan } \\
\text { bahaya limbah marmer, } \\
\text { mengabaikan generasi yang akan } \\
\text { datang, kontribusi yang diberikan } \\
\text { selalu membayar iuran dan } \\
\text { bersedekah. }\end{array}$ \\
\hline 2 & Informan 2 & $\begin{array}{l}\text { Tempat pembuangan limbah tidak } \\
\text { sesuai, kurang pemahaman akan } \\
\text { bahaya limbah marmer, } \\
\text { mengabaikan generasi yang akan } \\
\text { datang, kontribusi yang diberikan } \\
\text { selalu membayar iuran dan } \\
\text { bersedekah. }\end{array}$ \\
\hline 3 & Informan 3 & $\begin{array}{l}\text { Tempat pembuangan limbah tidak } \\
\text { sesuai, kurang pemahaman akan } \\
\text { bahaya limbah marmer, } \\
\text { mengabaikan generasi yang akan } \\
\text { datang, kontribusi yang diberikan } \\
\text { selalu membayar iuran dan } \\
\text { bersedekah. }\end{array}$ \\
\hline 4 & Informan 4 & $\begin{array}{l}\text { Tempat pembuangan limbah tidak } \\
\text { sesuai, kurang pemahaman akan }\end{array}$ \\
\hline
\end{tabular}


Indririyani, et al/Jurnal Ekonomi Syariah Teori dan Terapan Vol. 3 No. 8 Agustus 2016: 643-655; VALUASI EKONOMI DAN DAMPAK LINGKUNGAN AKIBAT INDUSTRI PENGOLAHAN MARMER DI DESA BESOLE KABUPATEN TULUNGAGUNG DI TINJAU DARI ESDAL PESPEKTIF ISLAM

\begin{tabular}{|c|l|l|}
\hline & & $\begin{array}{l}\text { bahaya limbah marmer, } \\
\text { mengabaikan generasi yang akan } \\
\text { datang, kontribusi yang diberikan } \\
\text { selalu membayar iuran dan } \\
\text { bersedekah. }\end{array}$ \\
\hline 5 & Informan 5 & $\begin{array}{l}\text { Tempat pembuangan limbah tidak } \\
\text { sesuai, kurang pemahaman akan } \\
\text { bahaya limbah marmer, } \\
\text { mengabaikan generasi yang akan } \\
\text { datang, kontribusi yang diberikan } \\
\text { selalu membayar iuran dan } \\
\text { bersedekah. }\end{array}$ \\
\hline
\end{tabular}

Sumber: diolah dari hasil wawancara, 2015

C. Dampak Lingkungan Industri Marmer Di Desa Besole Kabupaten
Tulungagung

Dampak lingkungan industri pengolahan marmer ini dirasakan oleh masyarakat ang bertempat tinggal berdekatan dengan tempat pengolahan marmer. Kesembila informan ketika ditanya pendapat mereka mengenai dampak yang mereka rasakan atas keberadaan tempat pengolahan marmer yag berdekatan dengan rumah mereka memiliki pendapat yang berbeda. Namun pendapat mereka memiliki substansi yang sama. Keluhan dampak yang mereka rasakan umumnya adalah berupa pencemaran udara yang diakibatkan semakin banyaknya debu yang dihasilkan dari truk truk pengangkut bahan baku marmer, pencemaran akibat limbah padat yang diakibatkan karene masih sangat minimnya tempat pembuagan limbah berupa lumpur marmer yang dihasilkan dari pemotongan marmer, dan juga pencemaran berupa energi yaitu kebisingan yang dihasilkan dari suara mesin pemotong marmer.
Tabel 4

Dampak Lingkungan Industri Marmer $\mathrm{Di}$ Desa Besole Kabupaten Tulungagun

\begin{tabular}{|c|c|c|c|}
\hline $\begin{array}{l}\text { Infor } \\
\text { man }\end{array}$ & $\begin{array}{l}\text { Pencemar } \\
\text { an udara }\end{array}$ & $\begin{array}{l}\text { Pencearan } \\
\text { akibat } \\
\text { limbah } \\
\text { padat }\end{array}$ & $\begin{array}{l}\text { Pencemara } \\
\text { n perupa } \\
\text { nergi }\end{array}$ \\
\hline 1 & $\begin{array}{l}\text { Banyak } \\
\text { debu }\end{array}$ & $\begin{array}{l}\text { Air sumur } \\
\text { direbus ada } \\
\text { kerak putih }\end{array}$ & $\begin{array}{l}\text { Suara mesin } \\
\text { keras }\end{array}$ \\
\hline 2 & $\begin{array}{l}\text { Kendaraa } \\
\mathrm{n} \quad \text { lalu } \\
\text { lalang }\end{array}$ & $\begin{array}{l}\text { Saat hujan } \\
\text { turun } \\
\text { berlumpur }\end{array}$ & $\begin{array}{l}\text { Terbiasa } \\
\text { dengan } \\
\text { suara mesin }\end{array}$ \\
\hline 3 & $\begin{array}{ll}\text { Kendaraa } \\
\mathrm{n} \quad \text { lalu } \\
\text { lalang }\end{array}$ & $\begin{array}{l}\text { Tidk } \\
\text { masalah }\end{array}$ & $\begin{array}{l}\text { Suara mesin } \\
\text { keras }\end{array}$ \\
\hline 4 & $\begin{array}{l}\text { Banyak } \\
\text { debu }\end{array}$ & $\begin{array}{l}\text { Hasil panen } \\
\text { menurun }\end{array}$ & $\begin{array}{l}\text { Terbiasa } \\
\text { dengan } \\
\text { suara mesin }\end{array}$ \\
\hline 5 & $\begin{array}{l}\text { Banyak } \\
\text { debu }\end{array}$ & $\begin{array}{l}\text { Dianggap } \\
\text { maklum }\end{array}$ & $\begin{array}{l}\text { Suara mesin } \\
\text { keras }\end{array}$ \\
\hline 6 & $\begin{array}{l}\text { Kendraan } \\
\text { lalu lalang }\end{array}$ & $\begin{array}{l}\text { Daun } \\
\text { tanaman } \\
\text { bercak } \\
\text { putih } \\
\end{array}$ & $\begin{array}{l}\text { Suara mesin } \\
\text { keras }\end{array}$ \\
\hline 7 & $\begin{array}{l}\text { Banyaknya } \\
\text { debu }\end{array}$ & Sudah biasa & $\begin{array}{l}\text { Terbiasa } \\
\text { dengan } \\
\text { suara mesin }\end{array}$ \\
\hline 8 & $\begin{array}{l}\text { Kendraan } \\
\text { lalu lalang }\end{array}$ & $\begin{array}{l}\text { Limbah } \\
\text { lumpur } \\
\text { meluber }\end{array}$ & $\begin{array}{l}\text { Suara mesin } \\
\text { keras }\end{array}$ \\
\hline 9 & $\begin{array}{l}\text { Banyaknya } \\
\text { debu }\end{array}$ & $\begin{array}{l}\text { Limbah } \\
\text { lumpur } \\
\text { meluber }\end{array}$ & $\begin{array}{l}\text { Suara mesin } \\
\text { keras }\end{array}$ \\
\hline
\end{tabular}

Sumber: diolah dari hasil wawancara, 2015

D. Analisis Ekonomi Sumber Daya Alam Dan Lingkungan Perspektif Islam

1. Al Istislah

Al istislah adalah memberikan perawatan terhadap lingkungan, teramasuk manusia namun mencakup pula kemaslahatan spesies-spesies yang ada di bumi. Melakukan perawatan dan pemeliharaan terhadap lingkungan menupakan tanggung jawab manusia. Allah SWT menciptakan alam dan seisinya untuk di manfaatkan secara optimal namun juga harus senantiasa memperhatikan keseimbangan dan kelestariannya. 
Indririyani, et al/Jurnal Ekonomi Syariah Teori dan Terapan Vol. 3 No. 8 Agustus 2016: 643-655; VALUASI EKONOMI DAN DAMPAK LINGKUNGAN AKIBAT INDUSTRI PENGOLAHAN MARMER DI DESA BESOLE KABUPATEN TULUNGAGUNG DI TINJAU DARI ESDAL PESPEKTIF ISLAM

Hasil wawancara yang dilakukan kepada lima pelaku industri marmer di Desa Besole terkait melakukan perawatan dan pemeliharaan terhadap lingkungan menunjukkan hasil yang hampir seragam. Para informan menuturkan bahwa kebanyakan tempat pengolahan marmer yang ada di desa besole dalam hal pengolahan limbah memang cenderung masih sangat sederhana. Menampung limbah lumpur dari sisa pemotongan di kolam tanah merupakan hal yang wajar dan sudah biasa dilakukan oleh kebanyakan pemilik tempat pengolahan marmer. Karena hal itulah ketika diajukan pertanyaan terkait anjuran dalam islam tentang pemeliharaan lingkungan kelima informan mengutarakan pernyataan bahwa menurut mereka kegiatan pengolahan marmer yang mereka lakukan tidak merusak lingkungan. Hal ini dikarenakan bertahun-tahun mereka menjalankan usaha tersebut tidak ada warga sekitar yang merasa dirugikan dan melakukan protes.

2. Pendekatan tujuan dasar islam (maqasiq al-syari'ah)

Memelihara lingkungan sama halnya dengan menjaga lima tujuan dasar islam (maqasia al-syari'ah). Dalam pembahasan ini dilakukan analisis terkait maqasid syariah dengan menggunakan tiga indikator yaitu memelihara jiwa (AnNafs), memelihara akal (Al- Aql)dan memelihara keturunan (An- Nasb)

a. Memelihara jiwa (an nafs)
Maksud memelihara jiwa di sini adalah memelihara hak untuk hidup secara terhormat dan memelihara jiwa agar terhindar dari tindakan penganiayaan , pembunuhan, maupun tindakan melukai lainnya. Islam sangat menjunjung tinggi jiwa manusia, sehingga dalam kegiatan apapun termasuk kegiatan ekonomi keselamatan jiwa perlu diutamakan.Wawancara dilakukan kepada informan yang berasal dari masyarakat terkait ada tidaknya dampak yang dirasakan dengan adanya tempat pengolahan marmer tersebut. Dari hasil wawancara yang dilakukan beberapa informan mengatakan bahwa memang ada dampak berupa pencemaran yang mereka rasakan dari adanya tempat pengolahan marmer tersebut

\section{b. Memelihara akal (alaql)}

Lingkungan yang sehat sering kali membantu manusia untuk berpikir jernih dan positif. Di sinilah industri memiliki peranan dalam menciptakan suasana yang tidak mengganggu akal pikiran masyarakat. Berkaitan dengan hal tersebut dilakukan wawancara yang berkaitan dengan pemeliharaan akal dengan indikator memelihara kenyamanan warga yang berdekatan dengan tempat pengolahan marmer. Dari hasil wawancara yang dilakukan diketahui bahwa kebanyakan warga yang bertempa tinggal berdekatan dengan tempat pengolahan marmer terganggu kenyamanannya dikarenakan bisingnya 
Indririyani, et al/Jurnal Ekonomi Syariah Teori dan Terapan Vol. 3 No. 8 Agustus 2016: 643-655; VALUASI EKONOMI DAN DAMPAK LINGKUNGAN AKIBAT INDUSTRI PENGOLAHAN MARMER DI DESA BESOLE KABUPATEN TULUNGAGUNG DI TINJAU DARI ESDAL PESPEKTIF ISLAM

alat pemotong marmer yang setiap harinya beroperasi.

c. Memelihara keturunan (an nasb) Indikator tujuan dasar islam yang ke empat adalah memelihara keturunan (an -nasb). Wawancara dilakukan untuk mengetahui bagaimana informan bertanggung jawab dalam memelihara keturunan (an-nasb). Indikator untuk memelihara keturunan adalah khawatir tidaknya informan terhadap habisnya bahan baku marmer sehingga mengakibatkan generasi mendatang tidak dapat menikmati. Dari hasil wawancara yang dilakukan diketahui bahwa kelima informan tidak merasa khawatir akan habisnya bahan baku marmer.

\section{KESIMPULAN}

Industri pengolahan marmer yang berada di Desa Besole Kabupaten Tulungagung telah memberikan dampak baik secara ekonomi maupun dampak bagi lingkunga sekitar tempat pengolahan marmer. Berdasarkan perhitungan NPV dan BCR yang telah dilakukan kepada lima tempat pengolahan marmer kelima industri menunjukkan nilai NPV dan BCR yang positif yang artinya layak dilakukan secara ekonomi. Meski demikian berdasarkan pengamatan dan wawancara yang dilakukan kepada warga Dsa Besole yang memiliki tempat tinggal berdekatan dengan tempat pengolahan marmer, tempat pengolahan marmer tersebut memberikan dampak yang negatif kepada mereka. Dampak negatif yang mereka rasakan adalah berupa pencemaran udara yang diakibatkan semakin banyaknya debu yang dihasilkan dari truk truk pengangkut bahan baku marmer, pencemaran akibat limbah padat yang diakibatkan karene masih sangat minimnya tempat pembuangan limbah berupa lumpur marmer yang dihasilkan dari pemotongan marmer, dan juga pencemaran berupa energi yaitu kebisingan yang dihasilkan dari suara mesin pemotong marmer.

Minimnya pengetahuan para pelaku usaha marmer dan juga faktor kebiasaan masyarakat yang cenderung membiarkan dampak yang mereka terima menjadi salah satu alasan mengapa para pelaku usaha marmer sering kali mengabaikan dampak yang timbul. Di lihat dari segi kesesuaian pemanfaatan sumber daya alam terlihat bahwa para pelaku industri marmer yang ada di Desa Besole masih mengabaikan kelestarian lingkungan. Hal ini ditunjukkan dengan tempat pembuangan limbah berupa lumpur yang kurang memadai, namun dianggap layak karena mayoritas tempat pengolahan marmer yang ada di desa tersebut menggunakan tempat pembuangan yang serupa. Selain itu para pelaku industri marmer tidak merasa khawatir apabila eksploitasi tambang marmer yang dilakukan untuk mendapatkan bahan baku habis. 
Indririyani, et al/Jurnal Ekonomi Syariah Teori dan Terapan Vol. 3 No. 8 Agustus 2016: 643-655; VALUASI EKONOMI DAN DAMPAK LINGKUNGAN AKIBAT INDUSTRI PENGOLAHAN MARMER DI DESA BESOLE KABUPATEN TULUNGAGUNG DI TINJAU DARI ESDAL PESPEKTIF ISLAM

Sehubungan dengan adanya dampak berupa pencemaran tersebut maka dilakukan tinjuan ESDAL perspektif islam dengan indikator istishlah dan maqasid syariah untuk mengetahui bagaimana pandangan islam akan permasalahan tersebut. Untuk istislah sendiri diketahui bahwa para pelaku industri pengolahan marmer masih belum sepenuhnya menjalankan pemeliharaan terhadap lingkungan. Sedangkan untuk maqasid syariah sendiri dari tiga indikator yang diajukan semuanya menunjukkan hasil yang tidak sesuai sehingga bisa dikatakan bahwa para pelaku industri marmer belum menjalankan tiga indikator maqasidsyariah dengan baik.

Saran yang dapat penulis sampaikan pada penelitian ini adalah :

1. Bagi para pelaku usaha marmer, mengingat masih belum memadainya tempat pembuangan limbah marmer berupa lumpur, diharapkan para pelaku usaha dapat lebih bijaksana dan bersedia membuat tempat pembuangan limbah yang lebih memadai dan sesuai standar sehingga dampak yang ditimbulkan dapat diminimalisir.

2. Bagi masyarakat Desa Besole agar dapat lebih terbuka dan kritis dalam menyikapi dampak yang dihasilkan dari adanya tempat pengolahan marmer dan tidak terkesan membiarkan, sehingga dampak yang dirasakan tidak berkepanjangan dan dapat segera di selesaikan.
3. Bagi pemerintah Desa Besole diharapkan dapat membuat kebijakan yang berkaitan dengan manajemen dampak yang disebabkan oleh tempat pengolahan marmer, sehingga dampak negatif yang ada dapat diminimalisir.

4. Bagi penelitian selanjutnya, dapat menggunakan metode perhitungan valuasi ekonomi yang lainnya serta diharapkan dapat menggunakan lebih banyak indikator-indikator ekonomi sumber daya alam perspektif islam yang lainnya sehingga lebih memperkaya penelitian di dibidang ESDAL perspektif islam.

\section{Daftar Pustaka}

Amsyari, F, 1996, Membangun Lingkungan Sehat Menyambut Lima Puluh Tahun Indonesia Merdeka, Surabaya, Airlangga University Press

Najwan, Johni, 2010, Perlindungan Dan Pengeloaan Lingkungan Hidup Dalam Perspektif Islam. Online Fh.Unja.Ac.Id/Index.Php/Jurnal Lingkungan Hidup

Putrantomo, Fazri, 2010, Aplikasi ContingentChoiceModelling (Ccm)

Dalam Valuasi Ekonomi Terumbu Karang Taman Nasional Karimunjawa, Bogor, Sekolah Pasca Sarjana IPB.

Qadir, Zuhal Abdul, 1997, Pembangunan Masyarakat Berdimensi IMTAQ Dan IPTEK (Edisi M. DawamRaharjo, Model Pembangunan QaryahThayyibah), Jakrta: Intermasa. 
Indririyani, et al/Jurnal Ekonomi Syariah Teori dan Terapan Vol. 3 No. 8 Agustus 2016: 643-655; VALUASI EKONOMI DAN DAMPAK LINGKUNGAN AKIBAT INDUSTRI PENGOLAHAN MARMER DI DESA BESOLE KABUPATEN TULUNGAGUNG DI TINJAU DARI ESDAL PESPEKTIF ISLAM

Reksohadiprojo, 1988, Ekonomi

Lingkungan, Jakarta, Karunika Jakarta

Safrilsyah Dan Fitriani, 2014, Agama Dan

Kesadaran Menjaga Lingkungan Hidup, Jurnal Substantial, Volume 16 Nomor 1

Soeharto, Iman, 2001, Studi Kelayakan

Proyek Industri, Jakarta, Erlangga

Soemarwoto, Otto . 1994. Analisis

Mengenai Dampak Lingkungan.

Yogyakarta, UGM Press

Sugiyono, 2008, Memahami Penelitian

Kualitatif, Bandung : Alfabeta

Suparmoko, 2009, Panduan Dan Analisis

Valuasi Ekonomi Sumber Daya Alam

Dan Lingkungan, Yogyakarta, BPFEYOGYAKARTA

Wihardi. M. Tjaronge, Dkk, 2006, Pecahan

Marmer Sebagai Pengganti Parsial

Agregat Kasar

SelfCompactingConcrete (SCC), Jurnal

Desain Dan Konstruksi. 